\title{
Frozen elephant trunk: debranch first technique
}

\author{
Paola Redaelli ${ }^{1}$, Igor Belluschi ${ }^{1}$, Luca Bertoglio ${ }^{2}$, Alessandro Verzini ${ }^{1}$, Roberto Chiesa ${ }^{2}$, \\ Alessandro Castiglioni ${ }^{1}$ \\ ${ }^{1}$ Department of Cardiac Surgery, ${ }^{2}$ Division of Vascular Surgery, IRCCS San Raffaele Scientific Institute, Milan, Italy \\ Correspondence to: Paola Redaelli. Department of Cardiac Surgery, IRCCS San Raffaele Scientific Institute, via Olgettina 60, 20132 Milan, Italy. \\ Email: redaelli.paola@hsr.it.
}

Submitted Nov 25, 2019. Accepted for publication Feb 18, 2020.

doi: $10.21037 /$ acs.2020.03.02

View this article at: http://dx.doi.org/10.21037/acs.2020.03.02

\section{Clinical vignette}

A 69-year-old male came to our attention because of a post-dissecting aortic arch aneurysm $\left(57 \times 53 \mathrm{~mm}^{2}\right)$. Two years before, he suffered from an intraoperative type A aortic dissection (TAAD) during mitral valve replacement, left atrial appendage closure and single coronary artery bypass grafting with the saphenous vein graft (SVG) on right coronary artery (RCA). The ascending aorta was then replaced with a $28 \mathrm{~mm}$ Dacron ${ }^{\circledR}$ prosthesis. Other comorbidities were hypertension, previous smoking and chronic limb ischemia. We planned an elective aortic arch replacement with debranch first (DF) technique in combination with a new custom-made Jotec E-Vita Open Plus ${ }^{\circledR}$ prosthesis $\left(24 \times 130 \mathrm{~mm}^{2}\right)$. Thoracic computed tomography angiography scan demonstrated occluded SVG on RCA, in presence of proper collateral circulation to RCA, and a circumferential pseudoaneurysm at the level of proximal anastomosis. Transthoracic echocardiography showed normal function of the mitral bioprosthesis, while left ventricle ejection fraction was $42 \%$ without regional wall motion abnormalities.

One month before arch surgery, a left carotid to subclavian bypass (LCSB) with endovascular occlusion of left prevertebral subclavian artery was performed $(14 \mathrm{~mm}$ Amplatzer ${ }^{\circledR}$ vascular plug II) to avoid left subclavian artery reimplantation at the time of frozen elephant trunk (FET) procedure.

\section{Surgical technique}

\section{Exposition}

Both axillary arteries were surgically isolated, and a termino-lateral anastomosis with a $8 \mathrm{~mm}$ vascular prosthesis was performed on both sides. After median sternotomy and adhesions detachment, cardiopulmonary bypass (CPB) was established. Arterial line was split into three parts, with cannulation of both axillary arteries and ascending aorta prosthesis (Seldinger technique). A right atrial two-stage cannula was inserted for venous drainage.

\section{Operation}

While reaching the target body temperature of $27{ }^{\circ} \mathrm{C}$ for moderate hypothermic circulatory arrest (MHCA), debranching of left common carotid and innominate arteries was performed by using a trifurcated $12 \times 8 \times 8 \mathrm{~mm}^{3}$ Maquet Hemashield ${ }^{\circledast}$ prosthesis. In the meanwhile, symmetrical and bilateral continuous antegrade cerebral perfusion (CACP) was granted by double axillary cannulation (10-15 $\mathrm{mL} / \mathrm{kg} / \mathrm{min}$ according to NIRS values). Visceral district was perfused through the central arterial line in ascending aorta prosthesis. As debranching was completed, ascending aorta prosthesis was cross-clamped and cold crystalloid cardioplegia was administered. The circumferential pseudoaneurysm was identified and excluded with Teflon strips, and proximal anastomosis with a $24 \mathrm{~mm}$ Vascutek Gelweave ${ }^{\circledR}$ prosthesis was performed.

At body temperature of $27^{\circ} \mathrm{C}$, the aortic clamp was removed and the distal aortic stump was prepared in zone 0 , below the innominate artery. The custom-made E-Vita Open Plus ${ }^{\circledR}$ graft was then inserted and released over a stiff guide-wire, previously introduced in the true lumen under transesophageal echocardiographic control through left common femoral artery. Distal FET anastomosis was performed using the sewing collar with a 3-0 polypropylene 
running suture.

As distal anastomosis was completed, the vascular section of the device was retracted from inside the aorta, and visceral perfusion was re-started through the distal side branch of the prosthesis. Proximal anastomosis between the two vascular grafts was performed during rewarming. Supraaortic vessels debranching was reimplanted with aortic sideclamping, using the proximal side branch of E-Vita Open Plus ${ }^{\circledR}$. The third branch of the trifurcated prosthesis was employed for de-airing.

\section{Completion}

Weaning from $\mathrm{CPB}$ required inotropic support with epinephrine, and perioperative hemostasis was achieved thanks to protamine and blood derivative products, according to rotational thromboelastometry.

Postoperative course was uneventful, and the patient was discharged to Cardiologic Rehabilitation ward on postoperative day 8. At late follow-up he is in good state of health with a stable residual chronic type B aortic dissection.

\section{Comments}

Promising preliminary results of DF technique have been previously reported by our group $(1,2)$ thanks to the new custom-made E-Vita Open Plus ${ }^{\circledR}$ prosthesis (3). It allows early visceral reperfusion after a short period of MHCA at $27-28^{\circ} \mathrm{C}$ and it facilitates debranching reimplantation. Distal anastomosis can be performed in zone 0 or 1 thanks to LCSB with endovascular occlusion of left subclavian artery and supra-aortic vessels debranching. This makes distal aortic stump suture less demanding from a technical point of view. The recommended cannulation strategy allows CACP during the whole procedure, preventing transient left cerebral hemisphere ischemia and further cannulas in the surgical field. Moreover, it preserves blood flow through both vertebral arteries, reducing the risk of paraplegia.

At present the main limitation of DF technique as described is that it cannot be performed in acute TAAD, because the custom-made E-Vita Open Plus ${ }^{\circledR}$ prosthesis requires 18 days for the manufacturing process, and the LCSB cannot be performed in a life-threatening setting. Left subclavian artery can be directly reimplanted on the trifurcated graft or ligated at its origin, performing a bypass to distal axillary artery. At the current moment a new model of E-Vita ${ }^{\circledR}$ prosthesis is under investigation for CE mark, and it will be probably available in the future for FET operations with DF technique even for emergency cases.

\section{Acknowledgments}

None.

\section{Footnote}

Conflicts of Interest: The authors have no conflicts of interest to declare.

Open Access Statement: This is an Open Access article distributed in accordance with the Creative Commons Attribution-NonCommercial-NoDerivs 4.0 International License (CC BY-NC-ND 4.0), which permits the noncommercial replication and distribution of the article with the strict proviso that no changes or edits are made and the original work is properly cited (including links to both the formal publication through the relevant DOI and the license). See: https://creativecommons.org/licenses/by-nc-nd/4.0/.

\section{References}

1. Castiglioni A, Redaelli P, Bertoglio L, et al. Debranch first technique in Frozen Elephant Trunk procedure: the experience of San Raffaele Hospital. In: Melissano G, Chiesa R. Aortic Complexities. Edi.Ermes, 2018.

2. Bertoglio L, Fittipaldi A, Giambuzzi I, et al. Preliminary results of debranch first technique in Frozen Elephant Trunk procedures. Ann Thorac Surg 2019;108:1345-53.

3. Bertoglio L, Castiglioni A, Grandi A, et al. Custom-made E-Vita graft for Frozen Elephant Trunk with arch-first technique. Ann Thorac Surg 2017;104:e467-9.
Cite this article as: Redaelli P, Belluschi I, Bertoglio L, Verzini A, Chiesa R, Castiglioni A. Frozen elephant trunk: debranch first technique. Ann Cardiothorac Surg 2020;9(3):257-258. doi: 10.21037/acs.2020.03.02 